\title{
Androgen receptor inclusions acquire GRP78/BiP to ameliorate androgen-induced protein misfolding stress in embryonic stem cells
}

\author{
Y-C Yang ${ }^{1,2,3,9}$, H-C Fu ${ }^{1,2,4,9}$, B-L Hsiao ${ }^{2,5,9}$, G Sobue ${ }^{6}$, H Adachi ${ }^{6}$, F-J Huang ${ }^{4}$, Y-D Hsuuw ${ }^{7}$, K-T Wei ${ }^{2}$, C Chang ${ }^{8}$, K-E Huang ${ }^{2,4}$ \\ and $\mathrm{H}-\mathrm{Y}$ Kang ${ }^{*, 1,2,5}$
}

Commitment of differentiating embryonic stem cells (ESCs) toward the various lineages is influenced by many factors, including androgens. However, the mechanisms underlying proteotoxic stress conferred by androgen receptor (AR) actions on embryonic cell fate remains unclear. Here we show that mouse ESCs display stress-related cellular phenotypes in response to androgens during early phase of differentiation. Androgen induced a significant increase in the percentage of ESCs and embryoid bodies with the intranuclear and juxtanuclear AR inclusions, which were colocalized with the E3 ubiquitin ligase, C terminus of Hsc70interacting protein. Caspase-3 activity corresponded with AR expression, was enhanced in cells engaged more differentiation phenotypes. Androgen-mediated accumulation of AR aggregates exacerbated endoplasmic reticulum (ER) stress and rendered ESCs susceptible to apoptosis. Increasing expression levels of the ER chaperones, GRP78/BiP and GRP94, as well as ER stress markers, such as ATF6, phosphorylated PERK, GADD153/CHOP and spliced XBP-1 mRNA, were dramatically elevated in ESCs overexpressing AR. We found that androgen induced GRP78/BiP to dissociate from ATF6, and act as an AR-interacting protein, which was recruited into AR inclusions in ESCs. GRP78/BiP was also colocalized with AR inclusions in the cells of spinal bulbar muscular atrophy transgenic mouse model. Overexpression of GRP78/BiP suppressed ubiquitination of AR aggregates and ameliorated the misfolded AR-mediated cytopathology in ESCs, whereas knockdown of GRP78/BiP increased the accumulation of AR aggregates and significantly higher levels of caspase-3 activity and cell apoptosis. These results generate novel insight into how ESCs respond to stress induced by misfolded AR proteins and identify GRP78/BiP as a novel regulator of the AR protein quality control.

Cell Death and Disease (2013) 4, e607; doi:10.1038/cddis.2013.122; published online 25 April 2013

Subject Category: Experimental Medicine

The embryonic stem cells (ESCs) have been established as sources to study a variety of endocrine systems, towing to their pluripotent ability to produce a seemingly unlimited supply of specific lineage of cell types, amenability to genetic engineering manipulations and broad developmental potential. ${ }^{1}$ Previously, we reported that high levels of androgen receptor (AR) were expressed in the inner cell mass (ICM) compared with the levels found in blastocysts and its expression level was stage-dependently increased during mouse ES cell differentiation. ${ }^{2}$ However, how ESCs respond to androgens, and functionality of the AR at the earliest stages of embryogenesis remains unclear.

From sex differentiation during embryogenesis to the onset and the maintenance of reproductive capacity in sexual maturity, androgen signaling is required for proper development and function. In rats $^{3}$ and mice, ${ }^{4}$ excess of testosterone $(T)$ or other androgens can cause infanticide, reduced litter size or low pup viability. ${ }^{5}$ In regard to human, enhanced ovarian androgen secretion is also associated with embryo degeneration. ${ }^{6}$ Functional $A R$ requires interaction with a wide variety of cellular proteins that facilitate $A R$ conformation, nuclear localization, DNA binding and interaction with the basal transcriptional machinery to induce expression of androgen-responsive AR-target genes. ${ }^{7-9}$ Abnormal conformation changes of the AR proteins, which alter its ability to bind androgens and coregulators, or maintain proper protein folding, lead to the formation of aggregated inclusions. $^{10}$

The presence of misfolded proteins elicits cellular responses, which include an endoplasmic reticulum (ER)

\footnotetext{
${ }^{1}$ Graduate Institute of Clinical Medical Sciences, Chang Gung University, College of Medicine, Kaohsiung, Taiwan; ${ }^{2}$ Center for Menopause and Reproductive Research, Kaohsiung Chang Gung Memorial Hospital, Kaohsiung, Taiwan; ${ }^{3}$ Department of Dermatology, Kaohsiung Chang Gung Memorial Hospital, Kaohsiung, Taiwan; ${ }^{4}$ Department of Obstetrics and Gynecology, Kaohsiung Chang Gung Memorial Hospital, Kaohsiung, Taiwan; ${ }^{5}$ Department of Biological Science, National Sun Yat-sen University, Kaohsiung, Taiwan; ${ }^{6}$ Department of Neurology, Nagoya University School of Medicine, Nagoya, Japan; ${ }^{7}$ Department of Life Science, National Ping-Tung University of Science Technology, Ping-Tung, Taiwan and ${ }^{8}$ George Whipple Lab for Cancer Research, University of Rochester, Rochester, NY, USA

${ }^{*}$ Corresponding author: H-Y Kang, Graduate Institute of Clinical Medical Sciences, Center for Menopause and Reproductive Research, Chang Gung Memorial HospitalKaohsiung Medical Center, Chang Gung University, College of Medicine, No.123 Dapi Road Niaosong District, Kaohsiung 83301, Taiwan. Tel: + 88677317123 ext 8898; Fax: + 8867733 6970; E-mail: hkang3@ @ail.cgu.edu.tw

${ }^{9}$ These authors contributed equally to this work.

Keywords: embryonic stem cells; androgen receptor; polyglutamine; spinal bulbar muscular atrophy; GRP78/BiP

Abbreviations: ESCs, embryonic stem cells;; AR, androgen receptor; polyQ, polyglutamine; SBMA, spinal bulbar muscular atrophy; EB, embryoid body; $\mathrm{DHT}$, dihydrotestosterone; T, testosterone; ICM, inner cell mass; UPR, unfolded protein response

Received 06.12.12; revised 01.3.13; accepted 05.3.13; Edited by M Agostini
} 
stress to induce the glucose-regulated proteins, such as GRP78/BiP and GRP94, and protect cells against the toxic buildup of misfolded proteins. ${ }^{11}$ However, accumulation of misfolded proteins in excessive amounts overwhelms the 'cellular quality control' system and impairs the protective mechanisms designed to promote correct folding and degrade faulty proteins, ultimately leading to organelle dysfunction and cell death. Previous studies showed that GRP78-/embryos did not hatch from the zona pellucida in vitro, failed to grow in culture, and exhibited proliferation defects and a massive increase in apoptosis in the $I C M{ }^{12}$ suggesting GRP78/BiP is required for cell proliferation and protecting the ICM from apoptosis.

Here, we present a novel insight in which AR proteins in ESCs form nuclear aggregated inclusions in response to androgen treatment, leading to exacerbated ER stress and cell death with apoptotic features during ESCs differentiation. We also identified GRP78/BiP is colocalized with AR inclusions in both ESCs and a mouse model of spinal bulbar muscular atrophy (SBMA). GRP78/BiP acts as an AR-associated protein to suppress ubiquitination of $A R$ aggregates, and required for amelioration of androgenmediated cytopathology of ESCs.

\section{Results}

Misfolded AR proteins inclusions are induced by differentiation or androgens in ESCs. To investigate the expression and localization of AR protein in different stages of ESCs, the ESCs and embryoid body (EB) culture systems were first treated with or without androgens for 3 days. Immunofluorescences staining revealed the AR protein inclusions are increased in EBs compared with ESCs, with or without dihydrotestosterone (DHT) treatment (Figure 1a). A significant increase in the percentage and size of intranuclear and juxtanuclear AR inclusions was detected in the DHTtreated EBs and different ESCs (Figure 1a and Supplementary Table 1). Western blot (WB) analysis further demonstrated aggregation of $A R$ with the high molecular weight was retained nearby the stacking gel (Figure $1 \mathrm{~b}$ ). Increasing AR aggregation associated with decreasing expression of Oct3/4, a stem cell marker for pluripotency of ESCs, was more prevalent in EBs, compared with ESCs, and addition of DHT enhanced the expression level of AR aggregates but not expression of Oct3/ 4 in ESCs (Figure 1b). AR aggregation and ubiquitinproteasome components have been detected in the polyglutamine (polyQ) protein inclusion complex of SBMA disease models. ${ }^{13-15}$ Accordingly, we performed immunofluorescence studies to determine whether any of these proteins are sequestered into DHT-induced inclusions. Indeed, ubiquitins and $\mathrm{C}$ terminus of Hsc70-interacting protein (CHIP), a U-box-type E3 ubiquitin ligase, were colocalized with AR inclusions induced by DHT (Figure 1c), possibly associated with ubiquitinated misfolded AR proteins.

\footnotetext{
AR is upregulated and required for apoptosis upon induction of ESC differentiation. Caspase cleavage is essential for apoptosis induced by AR aggregates in SBMA disease models. ${ }^{16,17}$ To gain an insight into the roles of $A R$ inclusions during ESC differentiation, caspase-3 activity and
}

AR expression were assessed with different ESC status. Caspase-3 activity corresponded with AR expression, was enhanced in the presence of DHT and this parallel was most evident in cells engaged more differentiation phenotypes (Figure 2a). Similarly, sustained caspase-3 activity and AR expression levels were both increased in a time-dependent manner, which was more evident in differentiated ESCs, compared with their undifferentiated counterparts (Figure 2b). To investigate the roles of androgen/AR in apoptosis activation of ESCs, ESC clones stably expressing either shAR or control short hairpin RNA (shRNA; shLuc) were first established (Figure $2 \mathrm{c}$ ) and treated with $\mathrm{DHT}, \mathrm{T}$ or nilutamide (N). WB analysis showed that the expression level of both AR monomers and aggregates were significantly decreased by shAR in EBs and ESCs. The procaspase-3 level was significantly increased and processed to its active form for caspase-3 activation in DHT- and T-treated ESCs with control shRNA, but remained largely unchanged in ESCs with AR knockdown (Figure 2d). N exerted an alleviative effect on androgen/AR-mediated caspase activation in ESCs (Figure 2d). PARP, a caspase-3 substrate, was also cleaved in control ESCs with the highest caspase-3 activities, but not AR knockdown ESCs (Figure 2d). We also detected a considerable decrease in the procaspase-12 level in both DHT- and T-treated ESCs transfected with control shRNA, but not those with AR knockdown (Figure 2d). To determine whether AR contributes to mediate apoptosis activation in ESC differentiation, TUNEL staining was used to compare apoptosis between ESCs and EBs stably expressing shAR or control shRNA. Consistent with caspase activation data, EBs contained more apoptotic cells than ESCs, and knockdown of AR expression significantly decreased in cell death in both ESCs and EBs (Figure 2e). Although neither the expression levels of stem cell selfrenewal markers, such as Nanog, GDF-3 and Oct3/4, nor the members of $\mathrm{Bcl}-2$ protein family were altered in ESCs stably overexpressing AR, overexpression of AR increased the expression of cyclin-dependent kinase inhibitors, p21 and p27, but decreased cyclin D1 and E expression (Supplementary Figure S1a) and promotion of ESCs apoptosis (Supplementary Figure S1b). To confirm androgen/AR apoptotic effects on mESCs ex vivo, we collected mouse blastocysts, the origin of ESCs, and incubated them with DHT. TUNEL and bisbenzimide staining assays were employed to analyze the index of nuclear labeling. The number of cells of mouse blastocysts displaying fragmented nuclei and positive TUNEL staining were increased upon DHT treatment (Table 1).

Activation of the UPR-signaling cascade by androgens/ AR in ESCs. Unfolded protein response (UPR) is a key switch of ER stress responses, which eventually triggers apoptosis if homeostasis of protein folding cannot be reestablished. ${ }^{18}$ We initially examined the upstream factors that sense ER stress in ESCs and EBs in response to DHT treatment, with a view to elucidating the mechanism of androgen-induced apoptosis. As activation of ATF6, PERK and IRE1 acts as ER-proximal UPR signal transducers, we first monitored the liberation of the cleaved ATF6 cytosolic fragment, ATF6f, and accumulation of phosphorylated PERK 
a

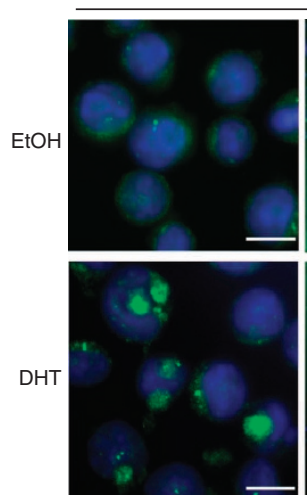

ESCs

\section{b}

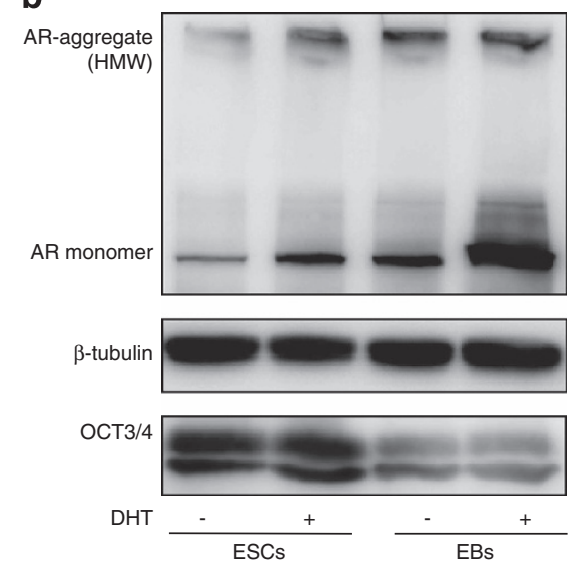

AR

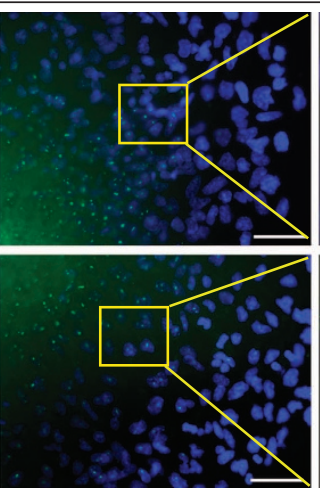

EBs
DAPI

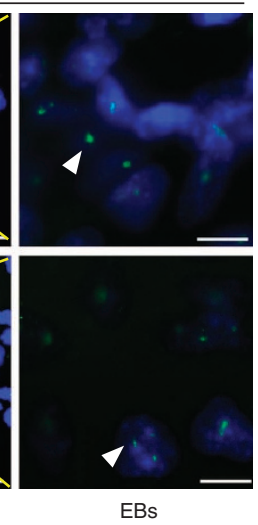

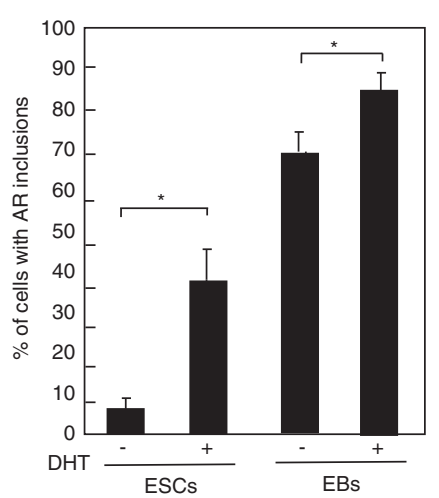

$\mathrm{EtOH}$

C $\mathrm{EtOH}$

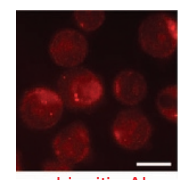

ubiquitin $\mathrm{Ab}$

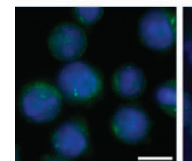

AR/DAPI

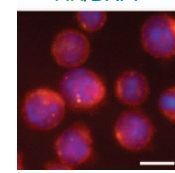

MERGE
DHT

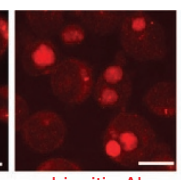

ubiquitin $\mathrm{Ab}$

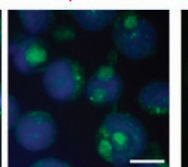

AR/DAPI

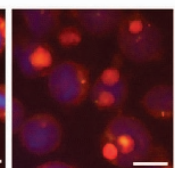

MERGE

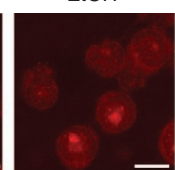

CHIP Ab

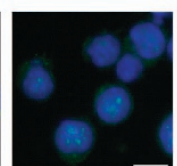

AR/DAPI

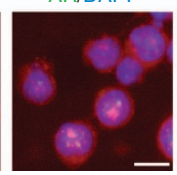

MERGE
DHT
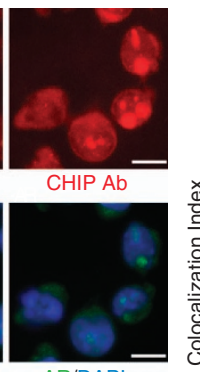

AR/DAPI

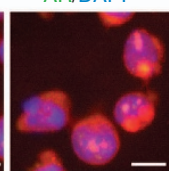

MERGE

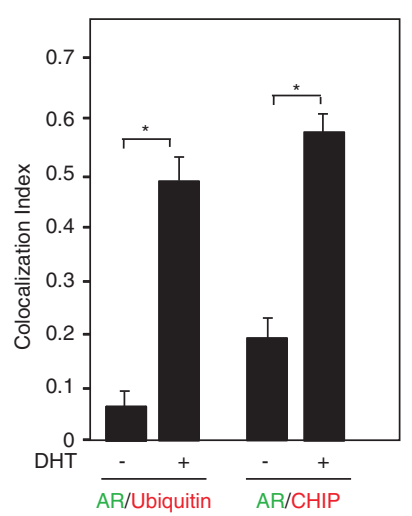

Figure 1 Androgen induces aggregation of AR protein with non-expanded polyQ tracts. (a) Immunofluorescence of ESCs revealed the formation of juxtanuclear and intranuclear inclusions of AR, which distort the nuclear architecture after treatment with DHT for 3 days (left panel). AR inclusions were also formed in EBs treated with DHT or left untreated for 3 days (middle panel). High-magnification images of the regions are indicated by arrows to show nuclear AR with small aggregates (right panel). Quantitation of cells with AR inclusions showed that DHT significantly promotes AR inclusions in ESCs whereas EBs exhibit a higher percentage of AR inclusions than ESCs, regardless of $\mathrm{DHT}$ treatment $(n=3)$. Data are presented as means \pm S.D. (b) The assay for steady-state protein expression showed that 3-day DHT treatment promoted AR aggregation, which was significantly increased in EBs compared with ESCs. Oct3/4 was used as a self-renewal marker and $\beta$-tubulin as a loading control. (c) Ubiquitin (red, top left panel) or CHIP (red, top right panel) partially colocalized with AR (green) and a higher colocalization index was observed after DHT treatment of ESCs for 3 days (merge). Scale bars: (ES) $10 \mu \mathrm{M}$; (EB) $50 \mu \mathrm{M}$. The quantification of the colocalization was performed by using the colocalization finder plugin of ImageJ. The colocalization index was estimated by Pearson's correlation coefficient; ${ }^{*} P<0.05$, ANOVA

and $\mathrm{XBP}-1^{\mathrm{s}}$ (the form of $\mathrm{XBP}-1$ derived from its spliced mRNA). WB analysis showed that ATF6f, phosphorylated PERK and $\mathrm{XBP}-1^{\mathrm{s}}$ were extensively processed to their active forms in EBs, but remained largely unaffected in ESCs (Figure 3a). We further determined whether androgen/AR had acquired means of promoting UPR activation under ER stress, by adding DHT to ESCs stably expressing AR, and comparing the expression levels of the active forms of UPR signaling proteins with those in parental ESCs. DHT induced an increase in the levels of ATF6f, phosphorylated PERK and spliced XBP-1 proteins in ESCs stably expressing AR (ESCs-FLAG-AR), compared with parental ESCs (ESCsFLAG; Figure 3b). Tunicamycin (TM), an agent that elicits ER stress by blocking $N$-linked glycosylation, also stimulated AR protein expression and promoted aggregation of wild-type AR (Figures $3 a$ and $b$ ). To ascertain the activation status of IRE1 after ER stress, we examined XBP-1 mRNA splicing in parental ESCs-FLAG and ESCs-FLAG-AR. We observed the expression of spliced $X B P-1$ mRNA was strongly induced in
ESCs-FLAG-AR, in comparison with ESCs-FLAG (Figure 3c). Similarly, the mRNA levels of Chop, a transcription factor induced by ATF4, ATF6 and XBP-1 to promote cell death in response to impaired ER stress, ${ }^{19}$ was significantly higher in ESCs-FLAG-AR than that in parental ESCs-FLAG. This DHT-mediated increase in spliced XBP-1 and Chop mRNA was time-dependent, displaying a higher fold increase with longer induction times (Figures $3 \mathrm{c}$ and d). Results also show that expression levels of the ER chaperones, GRP78/BiP and GRP94, were dramatically elevated in differentiated EBs and ESCs in response to DHT (Figures $3 b$ and c).

GRP78 Interacts With AR as a coregulator in ESCs. AR-interacting proteins have been characterized as transcriptional coregulators. ${ }^{9,20}$ However, the influence of AR-interacting proteins on AR misfolding and aggregation in response to cellular stress is poorly understood. To identify the androgen-dependent interacting proteins in the misfolded AR protein complex, we initially applied the yeast-two hybrid 
a

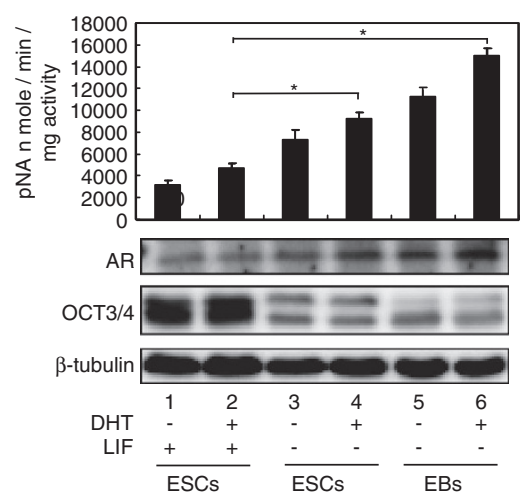

b

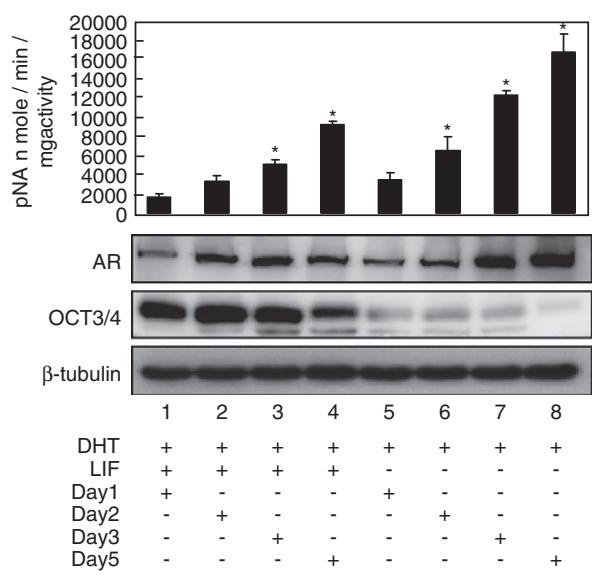

e

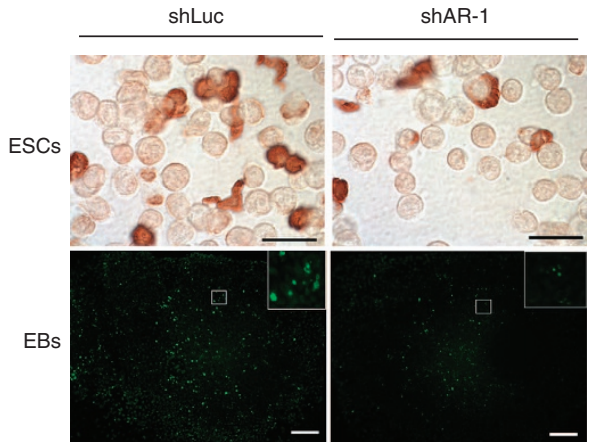

C

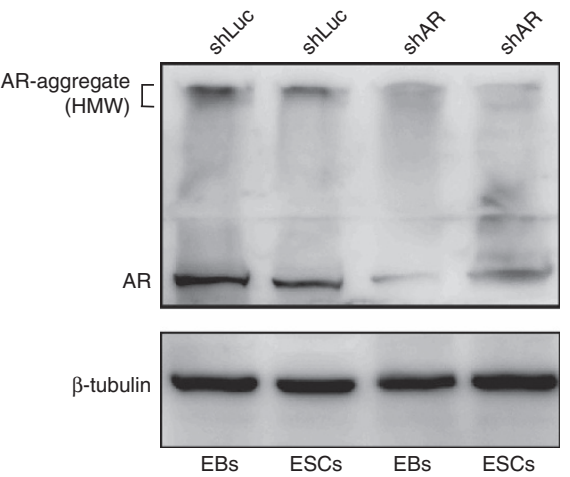

d
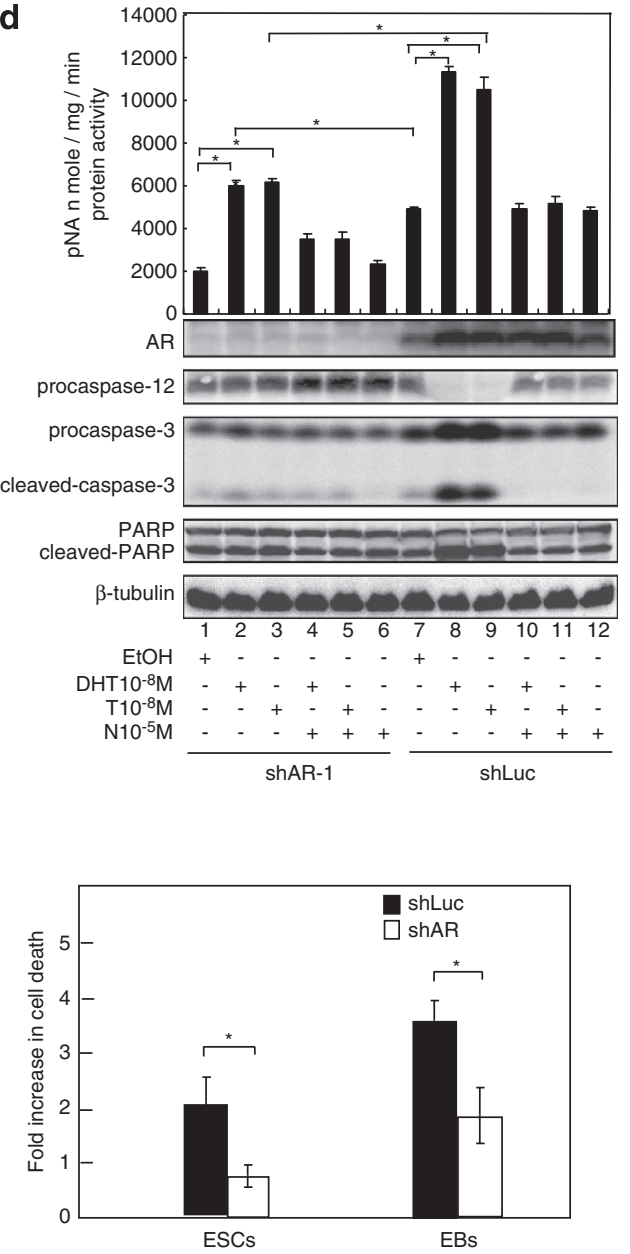

Figure 2 Increased AR expression and apoptosis upon induction of ES cell differentiation. (a) Caspase-3 activity assay (top panel) and WB analysis (bottom panel) showed a correlation between increasing expression of AR protein and induction of caspase-3 activity in undifferentiated ESCs, differentiated ESCs and EBs. Oct3/4 was employed as a self-renewal marker and $\beta$-tubulin as the loading control. (b) DHT-treated ESCs were cultured with LIF or left untreated for the indicated times. Both caspase-3 activity and AR expression showed a time-dependent increase from undifferentiated to differentiated ESCs. (c) Clones stably expressing either shAR or control shRNA (shLuc) were established in ESCs and EBs. (d) Caspase-3 activity assay and WB analysis using caspase-3, -12 and PARP antibodies showed a significant increase in activation of caspase-3 and -12 in control ESCs treated with DHT and T, but not ESCs expressing shAR. N suppressed the androgen-mediated effect in ESCs. (e) TUNEL staining of ESCs and EBs expressing shAR or shLuc. EBs contained more apoptotic cells than ESCs, and knockdown of AR led to significant suppression of cell death in both ESCs and EBs $\left(n=3,{ }^{*} P<0.05\right.$, ANOVA). Data are presented as means \pm S.D. The insert represents high magnification projections of apoptotic EB cells. Main image scale bars: (ESCs) $25 \mu \mathrm{M}$, (EBs) $100 \mu \mathrm{M}$

system to screen for potential proteins that interact with the misfolded AR complex under the influence of androgen treatment. Surprisingly, GRP78/BiP was associated with AR in the presence of $\mathrm{DHT}$ and $\mathrm{T}$ at concentrations $>1 \mathrm{nM}$, but not other steroids examined, including $17-\beta$-estradiol, hydroxyflutamide and 17-hydroxy-11-dehydrocorticosterone 
Table 1 Nuclear labeling index in androgen-pretreated blastocysts

\begin{tabular}{|c|c|c|c|c|c|c|}
\hline \multicolumn{7}{|c|}{$\begin{array}{c}\text { Nuclear labeling index in outgrowths of androgen-pretreated } \\
\text { blastocysts at } 72 \mathrm{~h}\end{array}$} \\
\hline & \multicolumn{3}{|c|}{ Control blastocysts } & \multicolumn{3}{|c|}{$\begin{array}{l}\text { DHT-pretreated } \\
\text { blastocysts }\end{array}$} \\
\hline & $n$ & ICM & TE & $n$ & ICM & TE \\
\hline $\begin{array}{l}\text { Fragmented nuclei } \\
\text { cells }\end{array}$ & 50 & $2.2 \pm 1.3$ & $1.2 \pm 0.7$ & 50 & $7.6 \pm 1.8$ & $1.0 \pm 0.8^{*}$ \\
\hline $\begin{array}{l}\text { TUNEL- } \\
\text { positive cells }\end{array}$ & 50 & $7.5 \pm 1.9$ & $2.0 \pm 1.3$ & 50 & $20 \pm 3.4$ & $5.3 \pm 1.0^{*}$ \\
\hline
\end{tabular}

Abbreviations: ICM, inner cell mass; $n$, number of outgrowths in each group; TE, trophectoderm

DHT pretreatment promoted apoptosis in blastocysts, appearing either as fragmented nuclei observed with the bisbenzimide trihydrochloride stain or DNA stand breaks, detected using TUNEL staining.

Data are presented as means \pm S.D.

The differences between the control and DHT-treated groups were analyzed with one-way ANOVA.

Results are given as the mean of labeled nuclei per outgrowth \pm S.D.

${ }^{*} P<0.05$ compared with the corresponding control value.

(Supplementary Figure S2a). To examine the possibility that DHT promotes in vivo interactions between AR and GRP78/ $\mathrm{BiP}$, ESCs were treated with $\mathrm{DHT}$, and immunoprecipitation experiments performed, followed by WB. As shown in Figure 4a, the endogenous AR-GRP78/BiP-associated protein complex was immunoprecipitated, in the presence of DHT. Similar results were obtained upon transfection with ARexpressing plasmids, further confirming that $A R$ is capable of interacting with GRP78/BiP (Figure 4b). A mammalian twohybrid system with the luciferase reporter gene assay was further confirmed androgen-dependent interactions between $\mathrm{AR}$ and GRP78/BiP in the presence of DHT or T (Supplementary Figure S2a). It is known that dissociation of GRP78/BiP from ATF6 is essential for proteolytic activation of ATF6 cleavage in response to ER stress. ${ }^{21}$ To determine whether DHT-induced interactions between GRP78/BiP and AR affect GRP78/BiP-ATF6 protein complex, ESCs transiently expressing 3xFLAG-tagged full-length ATF6 and AR were treated with or without DHT, and coimmunoprecipitation assays were performed to exam the interactions between GRP78/BiP and ATF6. As shown in Figure 4c, full-length ATF6 coimmunoprecipitated with GRP78/BiP in the absence of DHT, while treatment with $10 \mathrm{nM} \mathrm{DHT}$ for $72 \mathrm{~h}$ led to significant suppression of this interaction and increased the cleaved form of ATF6. Our data collectively suggest that DHT-AR is involved in the regulation of ATF6 activation by binding to GRP78/BiP, which then dissociates from ATF6, allowing its proteolytic activation.

GRP78 is a component of nuclear AR Inclusions in both ESCs and muscle cells from SBMA transgenic mice. Next, we examined the localization of GRP78/BiP associated with AR inclusions. ESCs and EBs were treated with DHT for $72 \mathrm{~h}$ and subjected to immunofluorescence staining of GRP78/BiP and AR. Both AR and GRP78/BiP were dispersed in the cytoplasm and nucleus in the absence of $\mathrm{DHT}$. The addition of $\mathrm{DHT}$ resulted in recruitment of GRP78/BiP to intranuclear inclusions of AR in both ESCs and EBs, as illustrated by the speckled staining pattern
(Figure 4d). To further confirm the direct interaction between GRP78/BiP and AR, ESCs were co-transfected with GFP-AR and DsRed-GRP78/BiP expression plasmids in the presence of DHT treatment. GFP-AR formed nuclear inclusions and colocalized with DsRed-GRP78/BiP in response to DHT (Supplementary Figure S3). It has been reported that the heat-shock protein (Hsp)70 and Hsp40 chaperone family members act together to suppress aggregation of misfolded AR proteins. $^{22}$ GRP78/BiP has also been shown to select misfolded protein substrates with these co-chaperones. ${ }^{23}$ To confirm whether these molecular chaperones are associated with AR in ESCs, coimmunoprecipitation assays were performed in ESCs treated with DHT. In agreement with the previous studies, AR was found to reciprocally coimmunoprecipitated with Hsp70, Hsp40 and GRP78 (Supplementary Figure S2b). In addition, we also discovered that GRP94, a member of the Hsp90 family and GRP78/BiP co-chaperone, was also recruited into nuclear inclusions in both ESCs and EBs in the presence of DHT, and interacted with AR (Supplementary Figures S2c-d). To further extend our observation, we investigated whether GRP78 also exists in polyQ-expanded $A R$ inclusion complex, which is the hallmark observed in the cells of SBMA transgenic mouse model. ${ }^{24}$ In agreement with previous studies, ${ }^{24}$ a significant increase in the percentage of cells with $A R$ inclusions was observed in the AR-97Q mice, compared with the AR-24Q mice (Figures $4 \mathrm{e}$ and $\mathrm{f}$ ). Double-immunofluorescence staining with anti-GRP78 and anti-polyQ antibodies revealed that intense staining of GRP78 in prominent inclusion bodies was detected in cells of both $A R-24 Q$ and $A R-97 Q$ mice, and a higher percentage of cells with the GRP78 and AR was colocalized in the intranuclear and juxtanuclear protein inclusions in the skeletal muscle fibers of the AR-97Q mice (Figures $4 \mathrm{~g}$ and $\mathrm{h}$ ).

\section{GRP78 overexpression suppresses ubiquitination of AR aggregates and inhibits the androgen/AR-mediated ESC} death. Molecular chaperones have been shown to interact with targeting misfolded AR proteins for ubiquitin-dependent pathways. ${ }^{15}$ To investigate whether GRP78/BiP modulate the ubiquitination of AR aggregates, we manipulated GRP78/ $\mathrm{BiP}$ expression and compared the ubiquitination of $\mathrm{AR}$ aggregates. In vivo ubiquitination assays showed that DHT induced both poly-and mono-ubiquitination of AR, whereas this ubiquitination was significantly abolished in the ESCs overexpressing GRP78/BiP (Figure 5a upper panel). Furthermore, immunoblotting revealed that overexpression of GRP78/BiP led to significantly reduce AR aggregation in the ESCs-FLAG-AR cells with DHT treatment (Figure $5 \mathrm{~b}$ bottom panel), whereas knockdown of GRP78/BiP in parental ESCs increased the accumulation of AR aggregates (Figure 5b). We also performed filter trap assays to quantitatively analyze the effects of GRP78/BiP overexpression on levels of both the large molecular aggregated and soluble forms of AR. Large aggregated AR complexes trapped by the cellulose acetate (CA) membrane were markedly reduced in the DHT-treated cells overexpressing GRP78/BiP, whereas levels of soluble monomeric AR protein trapped by the nitrocellulose (NC) membrane were only slightly reduced (Figure $5 \mathrm{c}$ ). We further investigated 
whether GRP78/BiP overexpression affected AR inclusions formation. As shown in Figure 5d, overexpression of GRP78/ BiP significantly decreased percentage of AR inclusions, and

conversely, GRP78/BiP knockdown led to an increased percentage of AR inclusions. To determine whether GRP78/ $\mathrm{BiP}$ regulates androgen/AR-induced apoptosis of ESCs,

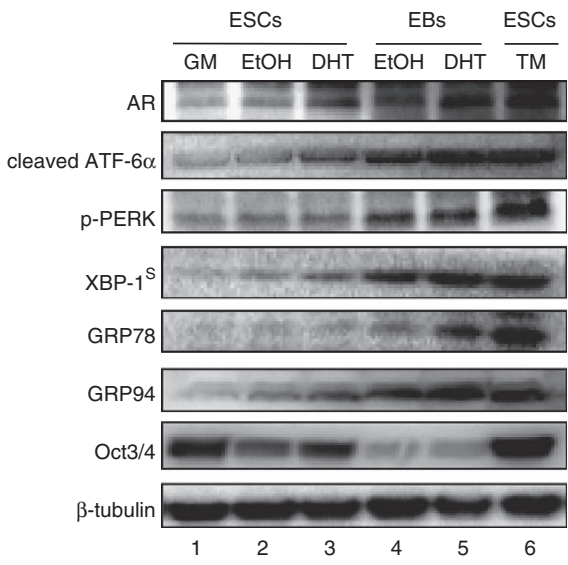

b

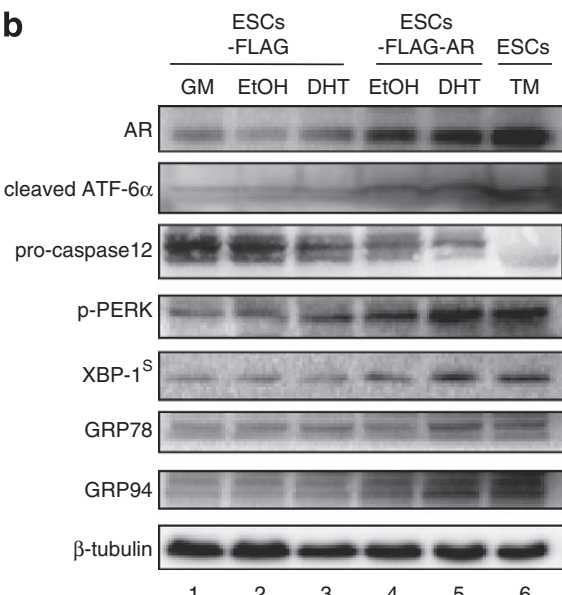

a

C

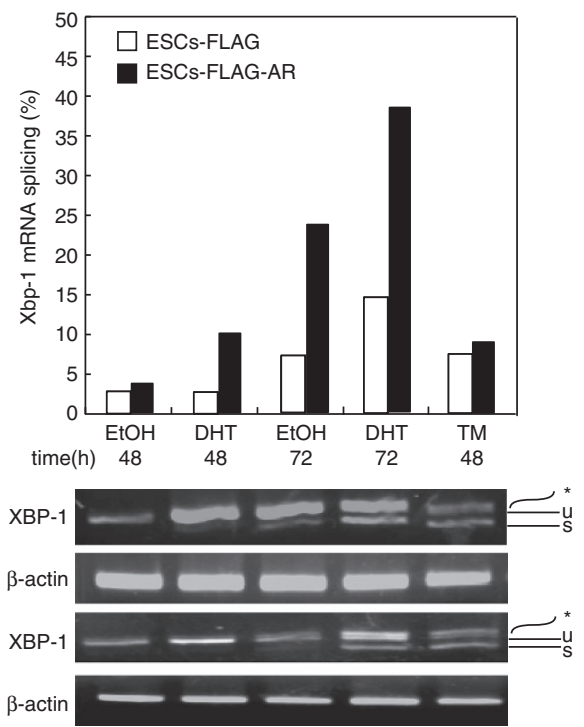

d

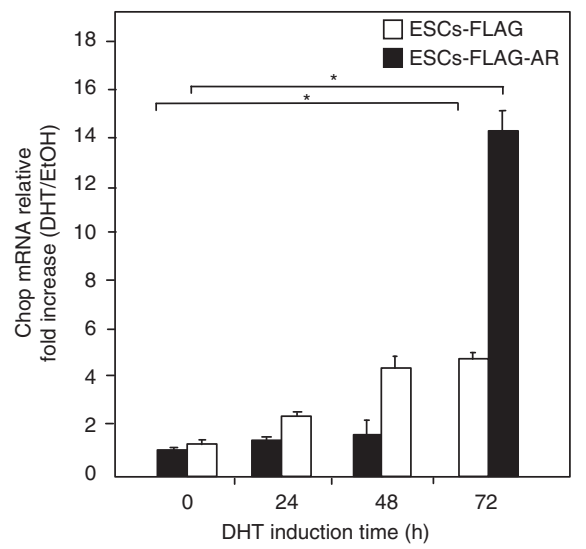

Figure 3 UPR signaling is activated by androgen/AR. (a) Expression and activation of UPR transducers (ATF-6 $\alpha$, p-PERK and XBP-1 ${ }^{5}$ ) and chaperones (GRP78 and GRP94) were increasingly detected in ESCs and EBs treated with DHT on WBs. Oct3/4 was used as a differentiation marker and $\beta$-tubulin as the loading control. General ES medium (GM) was used for basal level treatment and TM for ER stress induction. (b) ES cell clones stably expressing either AR (ESCs-FLAG-AR) or empty vector (ESCs-FLAG) were treated with DHT, or left untreated. WB analysis revealed increased expression and activation of UPR sensors and chaperones in ESCs-FLAG-AR in the presence of DHT. (c) In RT-PCR experiments, ESCs-FLAG-AR contained higher levels of spliced Xbp-1 mRNA than control ESCs-FLAG in a DHT- and time-dependent manner. Unspliced (u) and spliced (s) Xbp$1 \mathrm{mRNA}$ products are indicated. The asterisk ( ${ }^{*}$ ) represents the position of a hybrid amplicon. $\beta$-tubulin was used as the loading control and TM treatment as ER stress-induction control. (d) Real-time PCR data showed higher DHT-dependent Chop mRNA expression in ESCs-FLAG-AR than control ESCs-FLAG. ${ }^{\star} P<0.05$ was defined as significant

Figure 4 Androgens promote AR and GRP78/BiP interactions and colocalization with intranuclear AR inclusions in ESCs, EB and cells of a mouse model of SBMA. (a) The endogenous AR-GRP78/BiP protein complex was immunoprecipitated with anti-GRP78/BiP antibodies, but not anti-IgG control antibodies. (b) Overexpression of AR enhanced the DHT-induced interactions between AR and GRP78/BiP. The AR-GRP78/BiP complex was detected with an immunoprecipitation assay using anti-AR antibodies, followed by immunoblotting with anti-GRP78/BiP antibodies. (c) Decreasing association of GRP78/BiP with ATF6 in DHT-treated AR-expressing cells was detected via immunoprecipitation with anti- GRP78/BiP or anti-ATF6 antibodies and immunoblotting with anti- GRP78/BiP or anti-ATF6, respectively. (d) Nuclear AR inclusions colocalized with GRP78/BiP in DHT-treated ESCs and EBs. Scale bars: (ES) $10 \mu \mathrm{M}$; (EB) $50 \mu \mathrm{M}$. Immunofluorescence in muscle (e and f) sections from AR-24Q and AR-97Q mice revealed a marked increase in nuclear inclusions number of the AR-97Q mice compared with the AR-24Q mice. The boxed area shown at high-magnification images of the regions is a group of cells in an adjacent section, immunolabeled for AR and GRP78 (inset). Intense staining of PolyQ with small aggregates was frequently seen in the AR97Q mice, whereas staining was infrequently in the AR-24Q mice. (g) Colocalization of AR inclusions and GRP78 in muscle cells of the AR-24Q and AR-97Q mice by double immunofluorescence staining. The extent of colocalization of GRP78 and polyQ AR was higher in the cells of muscle from AR-97Q than AR-24Q mice. The quantification of the colocalization was performed by using the colocalization finder plugin of ImageJ. The index of colocalization corresponds to the mean of the Pearson's coefficient. (h) The histograms show the density of polyQ +/GRP78 + cells is significantly higher than polyQ-/GRP78 + , polyQ +/GRP78 - cells from both AR-24Q mice and AR-97Q mice, and a higher density in polyQ +/GRP78 + cells in muscle of the AR-97Q mice compared with the AR-24Q mice. Scale bars: (low-magnification image) $100 \mu \mathrm{M}$; (highmagnification image) $10 \mu \mathrm{M}$. ( $n=4$, mean \pm S.D., ${ }^{*} P<0.05$, ANOVA) 
ESCS-FLAG-AR and parental ESCs were examined in response to overexpression or knockdown of GRP78/BiP (Figures $6 a$ and b). TUNEL and caspase-3 activity assays revealed that knockdown of GRP78/BiP induced significantly higher levels of caspase-3 activity, and apoptosis were observed in ESCs-FLAG-AR and parental ESCs. Importantly, DHT-induced caspase-3 activity and cell death in ESCS-FLAG-AR was significantly alleviated by the reintroduction of GRP78/BiP (Figures 6a and b).

\section{Discussion}

The health and destiny of the cell is inextricably linked to protein quality control. Protein homeostasis is a highly complex network of molecular interactions that balances protein biosynthesis, folding, translocation, assembly/disassembly and clearance. ${ }^{25}$ Here, we propose the model depicted in Figure $6 \mathrm{c}$, which shows that misfolded AR proteins can be induced because of physiological fluctuations a

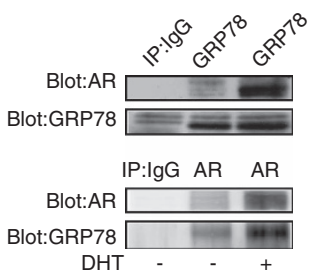

b

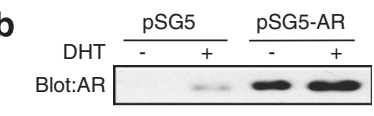

Blot:GRP78 $=-2$

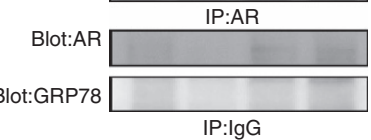

C

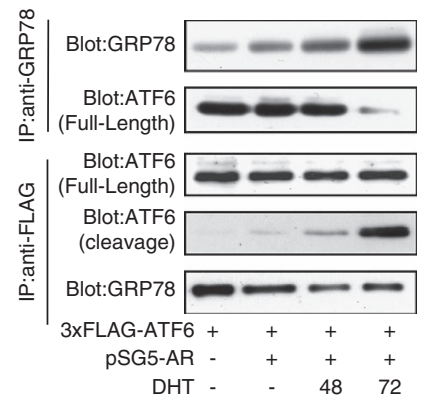

EBs
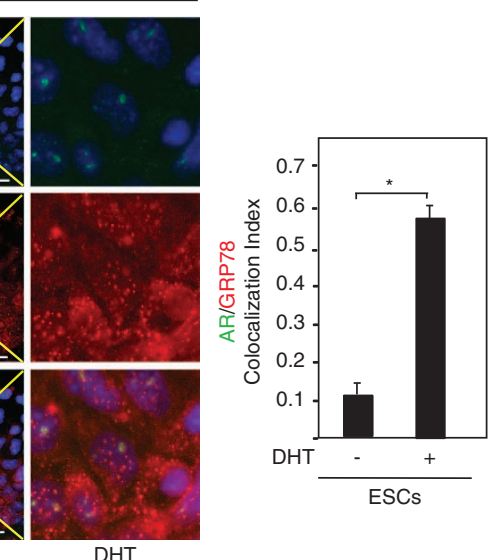

$\mathrm{EtOH}$

DHT
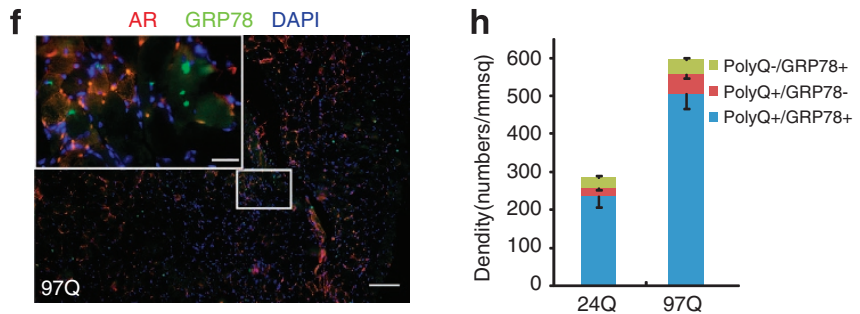

g
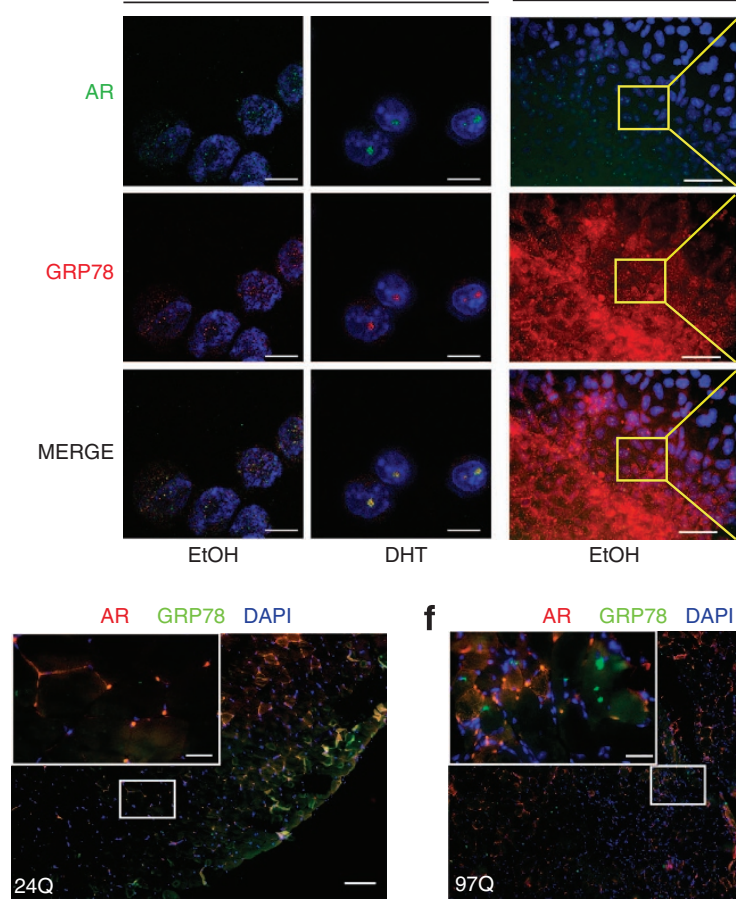

$\mathrm{DHT}$

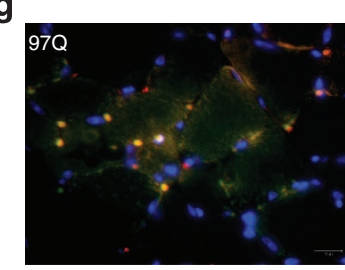

DAPI
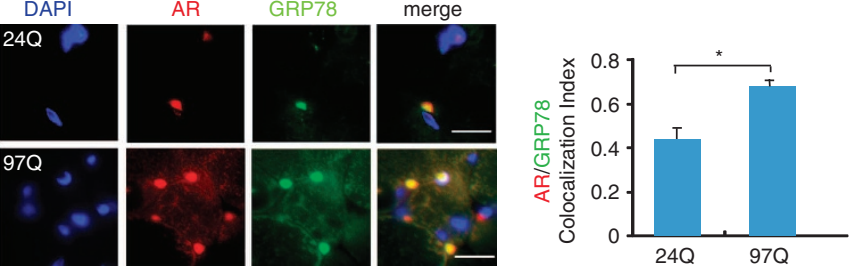


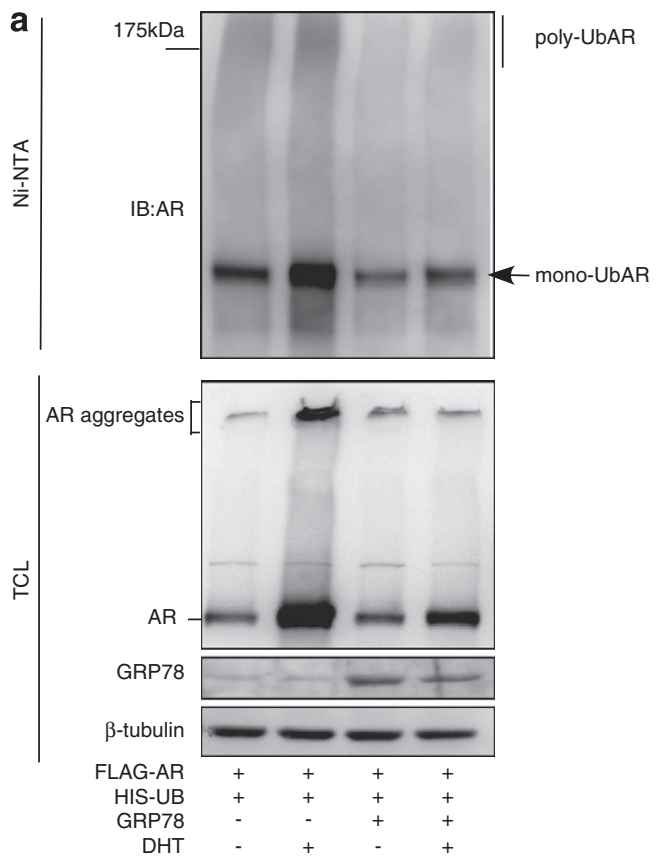

C

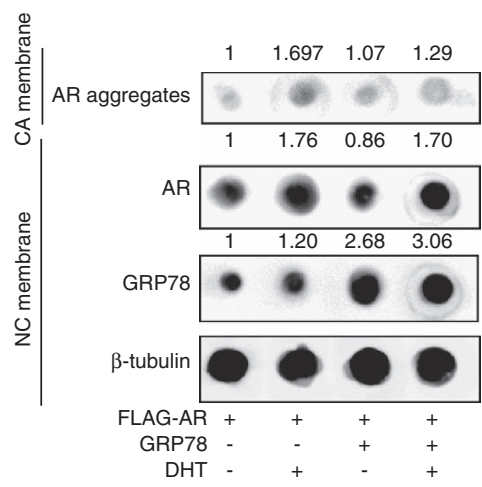

b

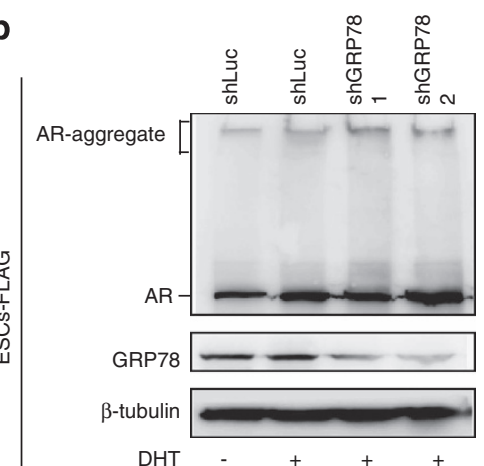

d
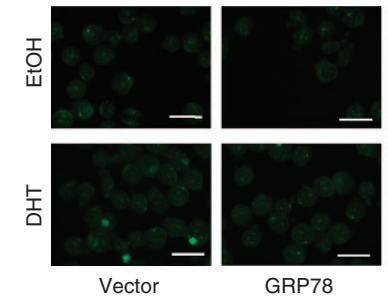

GRP78
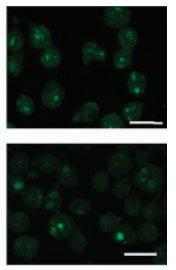

shGRP78

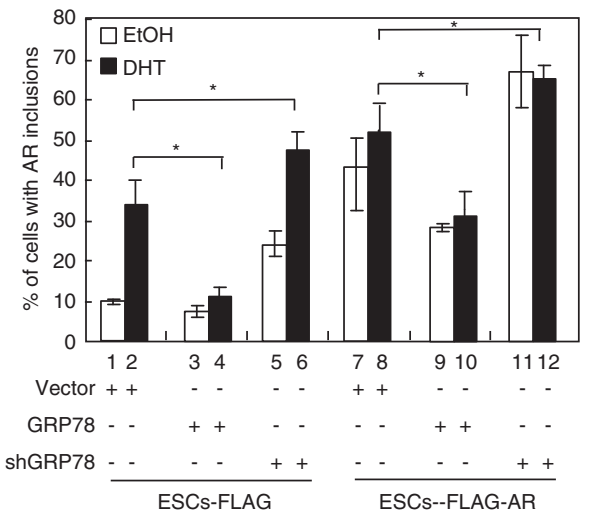

Figure 5 GRP78 is required for suppressing AR aggregation and androgen/AR-mediated ESC death. (a) Ubiquitination assay showed both poly-and mono-ubiquitination of AR were decreased in GRP78/BiP-overexpressing ESCs. (b) Knockdown of GRP78/BiP increases AR inclusions formation in ESCs with DHT treatment. (c) Flag-AR ESCs with GRP78 overexpression or vector control were treated with DHT for $72 \mathrm{~h}$. The high molecular weight AR aggregates were trapped in the CA membrane and the monomer AR was retained in the NC membrane. The expression of $\beta$-tubulin trapped in the NC membrane is shown as a loading control. (d) Immunofluorescence of AR aggregates in parental ESCs control and ESCs-FLAG-AR. GRP78/BiP expression regulate the AR aggregates accumulation. The percentage of cell with AR aggregates is shown. Data are presented as means \pm S.D., $n=3 .{ }^{*} P<0.05$ was defined as significant

(differentiation) or stress disturbance (androgens stimuli), and activate the ER stress to promote the expression of GRP78 through activation of ATF6 and XBP-1. The misfolded AR proteins are recognized and bound by GRP78, which may allow for the refolding of misfolded AR protein. However, if the misfolded AR proteins continue accumulation, it will form the toxic aggregates and eventually elicit an imbalance in homeostasis on the flux of misfolded AR proteins to result in deleterious consequences in ESCs.

Moreover, accumulation of aggregated AR inclusions and activation of the ER stress response observed in ESCs and EBs with androgen treatment bears a striking resemblance to those of several cell culture models of SMBA, which require overexpression of the expanded poly $Q$ tracts in mutant $A R$ proteins to form insoluble aggregates that are proteotoxic to cultured cells. ${ }^{22,26,27}$ These similarities in cytopathology between SBMA and our ESC model are surprising, because the length of polyQ tracts in the human $A R$ gene is polymorphic, whereas the intrinsic mouse $A R$ gene is not polymorphic and contains only 20 glutamine repeats, which the length of polyQ tracts is within the normal range (Supplementary Table S2), as verified by sequencing in several mouse ESCs. These results raise the intriguing question of how an endogenous protein with a non-expanded polyQ tract, such as $A R$, which typically promotes anabolic responses, can form aggregated inclusions in ESCs. We present evidence that activation of ER stress and downstream signaling pathways coincides with increasing AR protein expression in ESCs, which is possibly not an incidental phenomenon, but instead an active player in the early stages of mouse ESC differentiation. This may occur under perturbation of ER homeostasis or overloading of protein folding stimuli, such as androgens, which act as an effective stress signal to exhaust prosurvival efforts, encourage protein misfolding in ESCs that contains ER as a minimal structure in undifferentiated stages, but dramatically expands in differentiated stages. ${ }^{28}$ 
For each 'polyQ disease' protein, including ataxin-1, 29,30 $\alpha$-synuclein ${ }^{31}$ and tau, ${ }^{32}$ overexpression of the corresponding wild-type proteins induces a cytopathological phenotype similar to that of the mutant allele. Moreover, overexpression of wild-type $A R$ in muscle replicates polyQ disease in mouse models of SBMA, ${ }^{33,34}$ suggesting that an expanded polyQ a
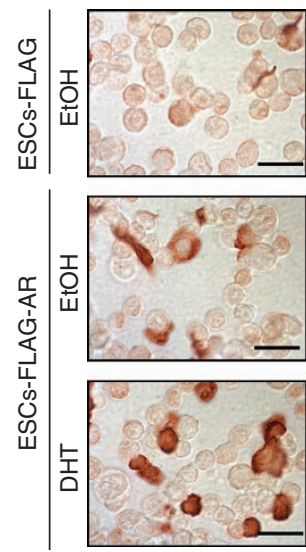

Vector
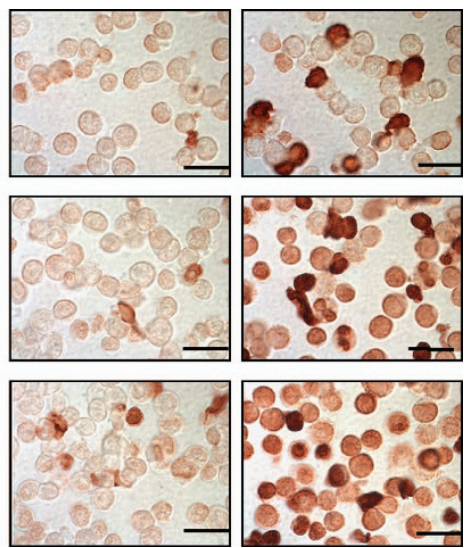

GRP78

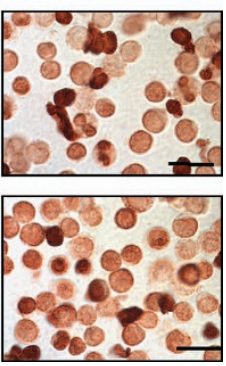

shGRP78 b

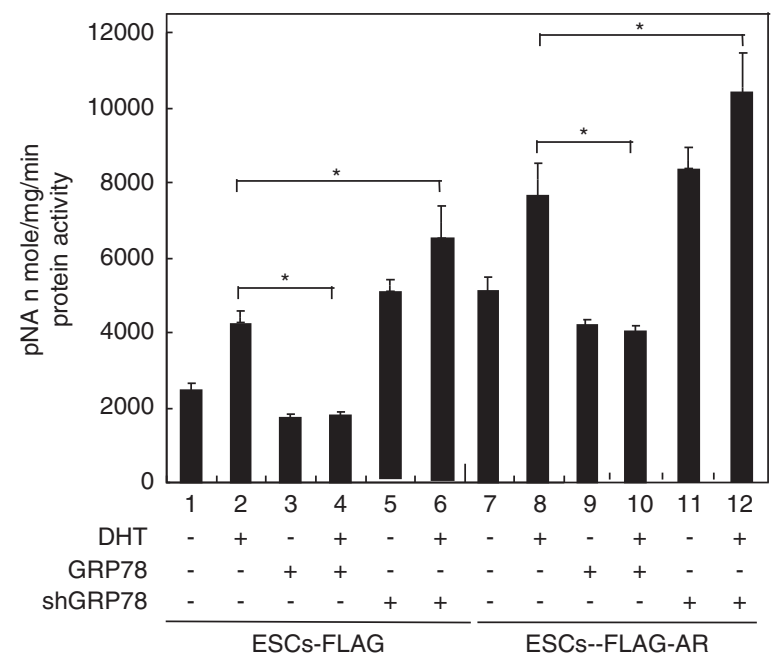

c

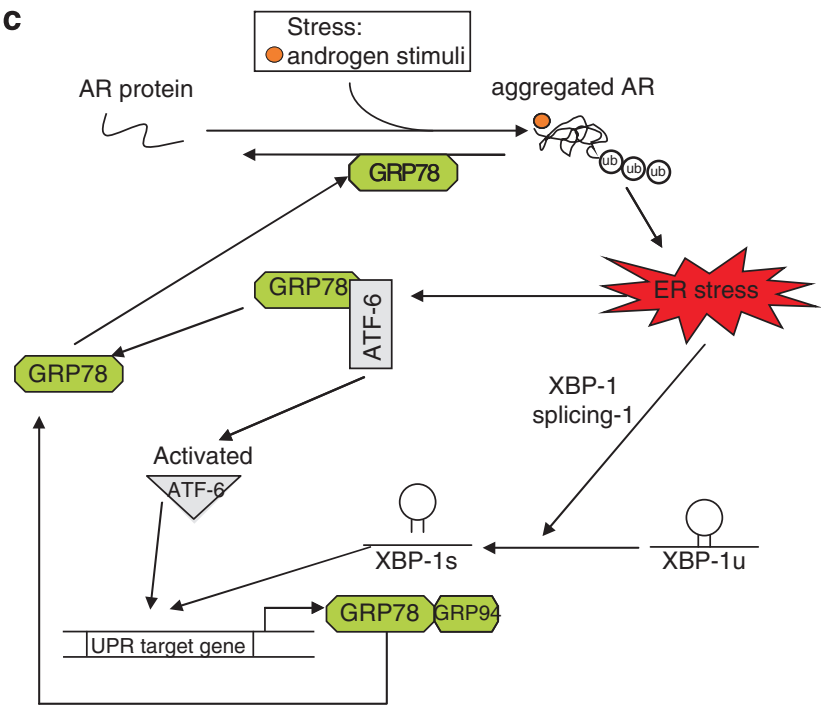

tract is not the only determining factor, and expression levels of specific proteins and unique cellular contexts may also be important factors of toxicity. Our finding that high levels of wild-type AR induced by differentiation and/or DHT treatment in mouse ESCs mimic the effects of expanded polyQ AR raises a number of intriguing open questions; for instance, the issues of whether the pluripotency and differentiation of ESCs is affected by DHT treatment. We found DHT suppressed the myogenic differentiation (Supplementary Figure S4) but the expression levels of stem cell pluripotency markers were unaltered, stably overexpressing AR in the present of DHT (Figure 1b and Supplementary Figure S1a). Another interesting question is whether all endogenous proteins associated with polyQ motifs trigger protein misfolding and ER stressinduced cell death in ESCs similar to that of AR. In viewing of our and other results, although AR proteins with polyQ motifs are conformationally aggregation-prone proteins, ESCs could be poorly adapted to ER stress only if the concentration of chaperones is titrated out as a result of association with accumulating protein aggregation by stress signals, such as androgens. Although ours is the first cell model to show that endogenous AR proteins with unexpanded polyQ tracts forms aggregated inclusions in ESCs comparable to those caused by the mutant disease proteins, whether human ES or iPS cell models might display similar misfolding protein phenotypes remains to be clarified.

The recent discovery that GRP78/BiP, a typical ER luminal chaperone and member of the Hsp70 family, can be alternatively expressed on the nucleus ${ }^{35-38}$ to interact with histone 3 and expanded polyQ Huntingtin aggregates, ${ }^{37,39}$ represents a paradigm shift in its biological function. However, the role of GRP78/BiP tracking from the ER to nucleus is not well understood. On the basis of our results, we propose that when AR protein misfolding occurs to induce ER stress, $\mathrm{GRP} 78 / \mathrm{BiP}$ is released from ATF6 in the ER, translocates into the nucleus and binds to nuclear AR aggregates in response to DHT treatment as an AR coregulator to exert cytoprotective function of chaperones. This could be a critical step for ESCs survival, as nuclear accumulation of misfolded proteins is most likely due to the lack or insufficiency of a secondary degradation mechanism within nuclei, and this accumulation of mutant protein is toxic to cells. Overexpression of the chaperones Hsp70 and Hsp40 suppresses aggregate formation and apoptosis in cultured neuronal cells, ${ }^{22,27}$ and ameliorates the phenotypes of the SBMA transgenic mouse model by reducing nuclear localized-mutant AR protein. ${ }^{40}$ Furthermore, the association of amyloid precursor protein with GRP78/BiP and overexpression of GRP78/BiP leads to

Figure 6 GRP78/BiP mitigates the misfolded AR-induced cytopathology. ESCs-FLAG-AR and ESCs-FLAG were treated with DHT $10^{-6} \mathrm{M}$ or vehicle control. (a) More ESCs-FLAG-AR were positive for TUNEL staining than control ESCsFLAG in response to DHT treatment. The number of TUNEL-positive cells was significantly reduced upon overexpression of GRP78/BiP, but increased upon GRP78/BiP knockdown. Scale bars: $25 \mu \mathrm{M}$. (b) Each value of caspase-3 activity was determined in triplicate. Both ESCs-FLAG-AR and ESCs-FLAG overexpressing GRP78/BiP exhibited a marked decrease in caspase-3 activity and cell death. Conversely, knockdown of GRP78/BiP expression promoted apoptosis. ${ }^{*} P<0.05$ was defined as significant. (c) Model for GRP78-dependent processing of misfolded AR proteins and aggregates formation. Numbers indicate various steps during misfolded AR proteins and aggregates biogenesis, as described in the discussion 
suppression of $\beta$-amyloid peptide production in an Alzheimer's disease model. ${ }^{41}$ In agreement with these reports, our experiments showed that overexpression of GRP78/BiP results in suppression of $A R$ protein ubiquitination and aggregation, and conversely, GRP78/BiP knockdown enhances AR aggregate formation, along with increasing levels of apoptosis via caspase- 3 activation in ESCs. In addition, GRP78/BiP was also colocalized with AR inclusions in the cells of SBMA transgenic mouse model. Together, we propose that GRP78/BiP is a critical mediator, which ameliorates the adverse effects of misfolded AR proteins and has cytoprotective roles in ESCs. In addition, these results also raise the important question as to whether ER molecular chaperones such as GRP78/BiP may function to suppress polyQ protein aggregation and cell death in SBMA disease. GRP78/BiP has been shown to select misfolded protein substrates with co-chaperones by recognizing the hydrophobic regions of the polypeptides that are usually exposed on the surface of unassembled proteins and maintain these proteins in their soluble conformations, preventing aggregation. ${ }^{23}$ In this regard, small molecular compounds have been described, which selectively induce GRP78/BiP expression without triggering the production of other UPR genes for neurodegenerative disease. ${ }^{42}$ Further studies are warranted to enhance GRP78/BiP function, promote the solubility or refolding of polyQ aggregates and reduce cellular pathology without conferring toxicity, thus presenting new therapeutic strategies of misfolded polyQ protein-related diseases.

\begin{abstract}
Materials and Methods
Reagents and antibodies. The following reagents and primary antibodies were used: DHT, T, TM (Sigma Chemical, St. Louis, MO, USA), N ; (Tocris, Bristol, UK), AR (N20, 1:400 dilution; Santa Cruz, Dallas, TX, USA), OCT3/4 (H134, 1:200; Santa Cruz), ubiquitin (P4D1, 1: 100; Santa Cruz), CHIP (C10, 1:500; Santa Cruz), Hsp70 (K20, 1:1000; Santa Cruz), Hsp40 (SPA-400, 1:5000; Stressgen, Victoria, BC, Canada), $\beta$-tubulin (I19, D10, 1:1000; Santa Cruz), pro-caspase 12 (N20, 1: 200; Santa Cruz), caspase 3 (L18, 1: 200; Santa Cruz), PARP (number 9542, 1:500; Cell Signaling, Boston, MA, USA), GRP78/ BiP (N20, 1:500; Santa Cruz), phospho-PERK (Thr980, 16F8, 1:400; Cell Signaling), FLAG (M2, 1:1000; Sigma), XBP-1 (M-186, 1:500; Santa Cruz), ATF-6a (H280, 1: 200; Santa Cruz), PolyQ(1C2) (MAB1574, 1:3000; Millipore, Billerica, MA, USA) MyoD (Sc-304, 1:10000; Santa Cruz), MyoHC (Sc-58797, 1:3000; Santa Cruz). pcDNA3-FLAG-AR and pSG5-AR have been described previously. ${ }^{2}$ pCMV-3xFLAG-ATF6 was obtained from Dr. Ron Prywes and pCMV6XL5-GRP78/BiP was purchased from Origene (Rockville, MD, USA). RNAi reagents were acquired from the National RNAi Core Facility at the Institute of Molecular
\end{abstract} Biology/Genomic Research Center, Academia Sinica, Taiwan.

Mouse ESC cell culture and differentiation. Mouse ES-D3 cell lines (ATCC, number CRL11632) were maintained on a feeder layer of mitomycin-Carrested STO fibroblasts (ATCC, number CRL1503) in DMEM (Invitrogen, catalog number10829-018, Grand Island, NY, USA) containing 15\% ES-qualified FBS (Innovative Research, Novi, MI, USA, catalog number IFBF-H), as described previously. ${ }^{2}$ To initiate EB formation, colonies were detached from the feeder layer with collagenase (Sigma, catalog number C-9263), re-incubated in medium without leukemia inhibitory factor (LIF; Esgro, Millipore, catalog number ESG1107), and cell clusters plated on feeder cell-free ultra-low attachment dishes. After 5 days, EBs were transferred to adherent, $0.1 \%$ gelatin type A (Sigma, catalog number G1890)-coated tissue culture dishes in media containing $10 \%$ charcoal-treated FBS, $1 \mathrm{nM}$ DHT or T (Sigma, A8380 and T1500), and harvested 3 days later for further analysis. For nonlineage-directed differentiation, EBs were cultured on Matrigel BD Biosciences (San Jose, CA, USA) in nonconditioned ES medium.
Apoptosis assay. The in situ cell death detection kit (Roche Pharmaceuticals, Nutley, NJ, USA catalog number 11684817 910) was used to identify apoptotic cells, according to the manufacturer's instructions. Caspase-3 activity was measured using a caspase-3 colorimetric activity assay kit (Chemicon Temecula, CA, USA, catalog number APT165), with Ac-DEVD-pNA as the substrate. The colorimetric reaction was developed and measured at $405 \mathrm{~nm}$ on a microtiter plate reader.

Immunocytochemistry. Cells were fixed in $4 \%$ paraformaldehyde or $1: 1$ acetone/methanol for $20 \mathrm{~min}$ at room temperature, followed by rinsing with PBS. Nonspecific labeling was blocked, and cells permeabilized with 5\% normal goat serum and/or 5\% normal donkey serum, containing $0.2 \%$ Triton X-100 in PBS for $30 \mathrm{~min}$ at room temperature. Cells were rinsed with PBS, and incubated with primary antibodies for $1 \mathrm{~h}$ at room temperature or overnight at $4{ }^{\circ} \mathrm{C}$. Next, cells were labeled with the appropriate fluorescent-tagged secondary antibodies. Slides were mounted with mounting medium containing 4,6-diamidino-2-phenylindole (Vector Laboratories, Burlingame, CA, USA) to label nuclei, sealed, and confocal images acquired with a Nikon C1 Laser Scanning Confocal microscope (Nikon instrument Inc., Melville, NY, USA). AR inclusions were counted in 100 nuclei, those positively stained with AR immunogenicity were counted, and measured on five areas on each of the three coverslips, using Image Pro Plus software (Media Cybernetics, Inc., Rockville, MD, USA). Quantitative colocalization was analyzed with the colocalization finder plugin of the Fiji image processing package based on ImageJ (US National Institutes of Health, Bethesda, MD, USA). ${ }^{43}$

Protein isolation and WB analysis. Cells were isolated, suspended in $1 \%$ Triton X-100 lysis buffer supplemented with $1 \%$ protease inhibitor cocktail (Sigma) and centrifuged at $16060 \times \mathrm{g}$ for $10 \mathrm{~min}$ at $4{ }^{\circ} \mathrm{C}$. Protein aliquots $(10-20 \mu \mathrm{g})$ were electrophoresed on a $10 \%$ SDS gel, transferred to a NC membrane and probed with the primary antibody for the indicated protein, followed by the application of horseradish peroxidase-conjugated secondary antiserum (Amersham, NJ, USA). Proteins were visualized using the ECL Plus kit (Amersham) and quantified with Bio-Rad Quantity One software (Hercules, CA, USA). As a control, the membrane was stripped and re-probed for $\beta$-tubulin.

Immunoprecipitation. Cells were rinsed once in ice-cold PBS and lysed in $1 \%$ Triton X-100 IP buffer (20 mM HEPES (pH 7.5), $150 \mathrm{mM} \mathrm{NaCl}, 1 \%$ Triton X-100, 10\% glycerol, $1 \mathrm{mM}$ EDTA and a protease inhibitor cocktail). After rotating for $1 \mathrm{~h}$ at $4{ }^{\circ} \mathrm{C}$, extracts were cleared by centrifugation at $13000 \times \mathrm{g}$ for $10 \mathrm{~min}$ at $4{ }^{\circ} \mathrm{C}$. AR, GRP78/BiP and ATF6 were immunoprecipitated with anti-FLAG M2 (1:200), anti-AR monoclonal $(1: 200)$ and anti-GRP78/BiP $(1: 100)$ antibodies, respectively, plus $20 \mu \mathrm{l}$ of $50 \%$ protein A Sepharose in IP buffer. Immunoprecipitates were washed three times with IP buffer, and the proteins resolved using SDS-PAGE. Proteins were transferred to NC membranes, and probed with the respective primary and horseradish peroxidase-conjugated secondary antibodies. The blots were visualized with ECL Plus reagents, according to the manufacturer's instructions.

RNA Interference and viral infection. For lentiviral shRNA infection, 293T cells were co-transfected with AR, GRP78 or GFP shRNA in pLKO.1-vector with packing plasmids (pCMV- $\triangle \mathrm{R} 8.91$ ) and envelope plasmid (VSV-G), using Lipofectamine 2000 reagent (Life Technologies, Carlsbad, CA, USA), according to the manufacturer's instructions. AR-lentiviral shRNA (5'-CCGCCGACATTAAAGA CATTT-3'), GRP78-lentiviral shRNA-1 (5'-CCGTACATTCAAGTTGATATT-3'), GRP78-lentiviral shRNA-2 (5'-CCCTTACACTTGGTATTGAAA-3') and Luc shRNA (5'-TCACAGAATCGTCGTATGCAG-3') were co-transfected with packing plasmids into 293T cells for 2 days, and virus particles containing AR, GRP78 or Luc shRNA used to infect ESCs to eliminate AR and GRP78 expression. All infected cells were cultured in medium containing the appropriate antibiotics.

Yeast and mammalian two-hybrid assays: The yeast two-hybrid assay was performed according to a previous report. ${ }^{20}$ Briefly, a pACT2 cDNA library consisting of a GAL4 activation domain (a.a. 768-881) fused with the mouse cDNA library was transformed into Y190 yeast cells with the GAL4 DNA-binding domain (DBD; a.a. 1-147). Transformants were selected for growth on nutrition selection plates (-histidine, -leucine and -tryptophan) containing different concentrations of DHT. Colonies were additionally filter assayed for $\beta$-galactosidase activity. DNA from positive clones was recovered from yeast, amplified in $E$. coli and confirmed by sequencing. In the mammalian two-hybrid 
assay, GRP78/BiP was fused with the GAL4 DBD in the pCMX expression vector and AR with the VP16 activation domain to generate PCMX-GAL4-GRP78/BiP and VP16-AR constructs, respectively. These plasmids and the pG5-luc reporter construct were transiently transfected into COS-1 cells, and luciferase activity measured, as described above.

RNA isolation and quantitative real-time PCR. Cells were lysed, total RNA collected (RNeasy, Qiagen, Hilden, Germany) and reverse transcription performed using the SuperScript-RT system (Invitrogen). Quantitative real-time $\mathrm{PCR}$ analyses using the comparative $C T$ method were performed on an $A B I$ PRISM 7700 Sequence Detector System, using the SYBR Green PCR Master Mix kit (Applied Biosystems, Foster City, CA, USA), as described previously. ${ }^{20}$ The primer sequences for murine CHOP used were: 5 -GCGACAGAGCCAGAATAA CAGC-3' and 5'-TTCTGCTTTCAGGTGTGGTGGT-3'; MyoD: 5'-CCC,CGG,CGG, CAG,AAT,GGC,TAC,G-3' and: $5^{\prime}$-GGT,CTG,GGT,TCC,CTG,TTC,TGT,GT-3'; MeoX-1: $5^{\prime}$-TGG,CCT,ATG,CAG,AAT,CCA,TTC,C-3' and $5^{\prime}$-GAG,ATC,TGA, GCT,GCG,CAT, GTG-3'; Pax3: 5'-TTT,CAC,CTC,AGG,TAA,TGG,GAC,T-3' and 5'-GAA,CGT,CCA,AGG,CTT,ACT,TTG,T-3'; Myogenin: 5'-TTA,CGG,GAG,AAA, ACT,CAC,GGC-3' and 5'-GGG,TCC,AAC,TTG,TCC,AGA,ATG,C-3'.

RT-PCR analysis of Xbp-1 splicing. Xbp-1 cDNA bearing the intron target of IRE $1 \alpha$ ribonuclease was employed as a template for amplification. The primers used for PCR, 5'-TTACGGGAGAAAACTCACGGC- $3^{\prime}$ and $5^{\prime}$-GGGTCCAACTTGTCCAGAATGC-3', were specific for murine Xbp-1. The PCR conditions were as follows: $95^{\circ} \mathrm{C}$ for $5 \mathrm{~min}, 95^{\circ} \mathrm{C}$ for $1 \mathrm{~min}, 58^{\circ} \mathrm{C}$ for $30 \mathrm{~s}$, $72{ }^{\circ} \mathrm{C}$ for $30 \mathrm{~s}$ and $72{ }^{\circ} \mathrm{C}$ for $5 \mathrm{~min}$, with 35 cycles of amplification. A 289-bp amplicon was generated from unspliced Xbp-1 and a 263-bp amplicon from spliced Xbp-1. PCR products were resolved on a $2.5 \%$ agarose $/ 1 \times$ TAE gel. As reported previously, a minor hybrid amplicon species consisting of unspliced $X b p-1$ annealed to spliced Xbp-1 was additionally generated, and appeared above the unspliced amplicon. ${ }^{44}$ Spliced Xbp-1 mRNA was quantified as a percentage of total Xbp-1 mRNA, using ImageQuant software (Amersham).

Double-immunofluorescence staining. Skeletal muscle tissues from AR $24 Q$ and AR97Q mice ${ }^{15}$ were collected, post-fixed overnight in $10 \%$ phosphate-buffered formalin and processed for paraffin embedding. Sections ( $6 \mu \mathrm{m}$ thick) of the above tissues were deparaffinized, dehydrated with alcohol and pretreated with microwave oven heating for $10 \mathrm{~min}$ in $10 \mathrm{mM}$ citrate buffer at $\mathrm{pH}$ 6.0 , and then in formic acid for $5 \mathrm{~min}$ at room temperature. For doubleimmunofluorescence staining of the skeletal muscle tissues, sections were blocked with $5 \%$ normal goat serum and then sequentially incubated with anti-GRP78 antibody and anti-polyQ antibody at $4{ }^{\circ} \mathrm{C}$ overnight. The sections were then incubated with Alexa 488-conjugated goat anti-rabbit IgG and Alexa 568conjugated goat anti-mouse IgG $\left(1: 500\right.$; Invitrogen) for $8 \mathrm{~h}$ at $4{ }^{\circ} \mathrm{C}$. The stained sections were examined and photographed with a fluorescence microscope (Nikon E800). For assessment of 1C2-positive cells in muscle, the number of 1C2-positive cells was calculated from counts of 500 fibers in randomly selected areas of individual mice and expressed as the number per millimeter. ${ }^{2}$ The quantitative data of six individual mice were expressed as means \pm S.D.

Filter-trap assay. AR aggregate filter-trap assay was measured according to previous studies. ${ }^{45}$ Cells were lysed by $0.1 \%$ SDS and the protein aliquots corresponding to $200 \mu \mathrm{g}$ of protein were filtered through $0.2 \mu \mathrm{m} \mathrm{CA} \mathrm{membrane}$ and $0.45 \mu \mathrm{m}$ NC membrane, as described above. Membranes were blocked with blocking buffers, and captured aggregates were detected by immunoblotting with AR or GRP78 antibody; proteins were visualized using the ECL Plus kit (Amersham). The total protein load was normalized to the volume of the soluble fraction.

Ubiquitination assay. In vivo ubiquitination assays were performed as described previously. ${ }^{46}$ In brief, ESCs were manipulated as the study design and harvested by denatured buffer $(6 \mathrm{M}$ guanidine $\mathrm{HCl}, 0.1 \mathrm{M} \mathrm{Na} 2 \mathrm{HPO} 4 / \mathrm{NaH} 2 \mathrm{PO} 4$, $10 \mathrm{mM}$ imidazole), followed by nickel bead purification and IB analysis. Proteins were eluted in SDS sample buffer, subjected to SDS-PAGE, transferred to NC membrane and immunoblotted with antibody.

Statistical analysis. All values are presented as means \pm S.D. of replicate samples ( $n=3-6$, depending on the experiment), and experiments were repeated a minimum of three times. Differences between the two groups were assessed using the unpaired two-tailed Student's $t$ test or among more than two groups with ANOVA. Tukey's test was used as a post-hoc analysis in ANOVA for assessing the significance of pairwise group comparisons. In all statistical comparisons, $P<0.05$ was defined as significant. The SPSS statistics software (version 10.0; IBM Corporation, Armonk, NY, USA) was used for all calculations.

\section{Conflict of Interest}

The authors declare no conflict of interest.

Acknowledgements. We thank Dr. Hui-Kuan Lin for comment on the manuscript. This work was supported by Grants CMRPD 8708431-3, 8911181-3, CMRPG 860261-3 and 890911-2 from Chang Gung Memorial Hospital and NMRPD 170341-3 (NSC97-2321-B-182-004-MY3) from the National Science Council to Dr. Hong-Yo Kang.

1. Wichterle $\mathrm{H}$, Przedborski $\mathrm{S}$. What can pluripotent stem cells teach us about neurodegenerative diseases? Nat Neurosci 2010; 13: 800-804

2. Chang CY, Hsuuw YD, Huang FJ, Shyr CR, Chang SY, Huang CK et al. Androgenic and antiandrogenic effects and expression of androgen receptor in mouse embryonic stem cells. Fertil Steril 2006; 85(Suppl 1): 1195-1203.

3. Rosenberg KM, Sherman GF. Testosterone induced pup-killing behavior in the ovariectomized female rat. Physiol Behav 1974; 13: 697-699.

4. Mann MA, Svare B. Prenatal testosterone exposure elevates maternal aggression in mice. Physiol Behav 1983; 30: 503-507.

5. Fritz H, Giese K, Suter HP. Prenatal and postnatal development of rats following the maternal treatment with testosterone during the late period of embryogenesis. Arzneim Forsch 1984; 34: 780-782.

6. Yun YW, Yuen BH, Moon YS. Effects of an antiandrogen, flutamide, on oocyte quality and embryo development in rats superovulated with pregnant mare's serum gonadotropin. Biol Reprod 1988; 39: 279-286.

7. Heinlein $\mathrm{CA}$, Chang $\mathrm{C}$. Androgen receptor (AR) coregulators: an overview. Endocr Rev 2002; 23: 175-200.

8. Kang Z, Janne OA, Palvimo JJ. Coregulator recruitment and histone modifications in transcriptional regulation by the androgen receptor. Mol Endocrinol 2004; 18: 2633-2648.

9. Kang HY, Tsai MY, Chang C, Huang KE. Mechanisms and clinical relevance of androgens and androgen receptor actions. Chang Gung Med J 2003; 26: 388-402.

10. Thomas M, Yu Z, Dadgar N, Varambally S, Yu J, Chinnaiyan AM et al. The unfolded protein response modulates toxicity of the expanded glutamine androgen receptor. $\mathrm{J}$ Biol Chem 2005; 280: 21264-21271.

11. Rao RV, Bredesen DE. Misfolded proteins, endoplasmic reticulum stress and neurodegeneration. Curr Opin Cell Biol 2004; 16: 653-662.

12. Luo $S$, Mao C, Lee B, Lee AS. GRP78/BiP is required for cell proliferation and protecting the inner cell mass from apoptosis during early mouse embryonic development. $\mathrm{Mol} \mathrm{Cell}$ Biol 2006; 26: 5688-5697.

13. Rubinsztein DC. The roles of intracellular protein-degradation pathways in neurodegeneration. Nature 2006; 443: 780-786.

14. Bence NF, Sampat RM, Kopito RR. Impairment of the ubiquitin-proteasome system by protein aggregation. Science 2001; 292: 1552-1555.

15. Adachi H, Waza M, Tokui K, Katsuno M, Minamiyama M, Tanaka $F$ et al. CHIP overexpression reduces mutant androgen receptor protein and ameliorates phenotypes of the spinal and bulbar muscular atrophy transgenic mouse model. J Neurosci 2007; 27: 5115-5126.

16. Ellerby LM, Hackam AS, Propp SS, Ellerby HM, Rabizadeh S, Cashman NR et al. Kennedy's disease: caspase cleavage of the androgen receptor is a crucial event in cytotoxicity. J Neurochem 1999; 72: 185-195

17. Kobayashi Y, Miwa S, Merry DE, Kume A, Mei L, Doyu M et al. Caspase-3 cleaves the expanded androgen receptor protein of spinal and bulbar muscular atrophy in a polyglutamine repeat length-dependent manner. Biochem Biophys Res Commun 1998; 252: $145-150$.

18. Kim I, Xu W, Reed JC. Cell death and endoplasmic reticulum stress: disease relevance and therapeutic opportunities. Nat Rev Drug Discov 2008; 7: 1013-1030.

19. Zinszner H, Kuroda M, Wang X, Batchvarova N, Lightfoot RT, Remotti $\mathrm{H}$ et al. $\mathrm{CHOP}$ is implicated in programmed cell death in response to impaired function of the endoplasmic reticulum. Genes Dev 1998; 12: 982-995.

20. Kang HY, Lin HK, Hu YC, Yeh S, Huang KE, Chang C. From transforming growth factor-beta signaling to androgen action: identification of Smad3 as an androgen receptor coregulator in prostate cancer cells. Proc Natl Acad Sci USA 2001; 98: 3018-3023.

21. Shen J, Chen X, Hendershot L, Prywes R. ER stress regulation of ATF6 localization by dissociation of BiP/GRP78 binding and unmasking of Golgi localization signals. Dev Cell 2002; 3: 99-111. 
22. Kobayashi Y, Kume A, Li M, Doyu M, Hata M, Ohtsuka K et al. Chaperones Hsp70 and Hsp40 suppress aggregate formation and apoptosis in cultured neuronal cells expressing truncated androgen receptor protein with expanded polyglutamine tract. J Biol Chem 2000; 275: 8772-8778.

23. Flynn GC, Pohl J, Flocco MT, Rothman JE. Peptide-binding specificity of the molecular chaperone BiP. Nature 1991; 353: 726-730.

24. Katsuno M, Adachi $H$, Inukai $A$, Sobue $G$. Transgenic mouse models of spinal and bulbar muscular atrophy (SBMA). Cytogenet Genome Res 2003; 100: 243-251.

25. Morimoto RI. Proteotoxic stress and inducible chaperone networks in neurodegenerative disease and aging. Genes Dev 2008; 22: 1427-1438.

26. Walcott JL, Merry DE. Ligand promotes intranuclear inclusions in a novel cell model of spinal and bulbar muscular atrophy. J Biol Chem 2002; 277: 50855-50859.

27. Bailey CK, Andriola IF, Kampinga HH, Merry DE. Molecular chaperones enhance the degradation of expanded polyglutamine repeat androgen receptor in a cellular model of spinal and bulbar muscular atrophy. Hum Mol Genet 2002; 11: 515-523.

28. Oh SK, Kim HS, Ahn HJ, Seol HW, Kim YY, Park YB et al. Derivation and characterization of new human embryonic stem cell lines: SNUhES1, SNUhES2, and SNUhES3. Stem Cells 2005; 23: 211-219.

29. Tsuda H, Jafar-Nejad H, Patel AJ, Sun Y, Chen HK, Rose MF et al. The AXH domain of Ataxin-1 mediates neurodegeneration through its interaction with Gfi-1/senseless proteins. Cell 2005; 122: 633-644.

30. Fernandez-Funez P, Nino-Rosales ML, de Gouyon B, She WC, Luchak JM, Martinez P et al. Identification of genes that modify ataxin-1-induced neurodegeneration. Nature 2000; 408: 101-106.

31. Singleton AB, Farrer M, Johnson J, Singleton A, Hague S, Kachergus J et al. Alphasynuclein locus triplication causes Parkinson's disease. Science 2003; 302: 841.

32. Wittmann CW, Wszolek MF, Shulman JM, Salvaterra PM, Lewis J, Hutton M et al. Tauopathy in Drosophila: neurodegeneration without neurofibrillary tangles. Science 2001; 293: $711-714$

33. Huguenard AL, Fernando SM, Monks DA, Sengelaub DR. Overexpression of androgen receptors in target musculature confers androgen sensitivity to motoneuron dendrites. Endocrinology 2011; 152: 639-650.

34. Monks DA, Johansen JA, Mo K, Rao P, Eagleson B, Yu Z et al. Overexpression of wild-type androgen receptor in muscle recapitulates polyglutamine disease. Proc Natl Acad Sci USA 2007; 104: 18259-18264.

35. Munro S, Pelham HR. An Hsp70-like protein in the ER: identity with the $78 \mathrm{kd}$ glucoseregulated protein and immunoglobulin heavy chain binding protein. Cell 1986; 46 : 291-300.
36. Morris JA, Dorner AJ, Edwards CA, Hendershot LM, Kaufman RJ. Immunoglobulin binding protein $(\mathrm{BiP})$ function is required to protect cells from endoplasmic reticulum stress but is not required for the secretion of selective proteins. J Biol Chem 1997; 272: 4327-4334.

37. Matsumoto A, Hanawalt PC. Histone $\mathrm{H} 3$ and heat shock protein GRP78 are selectively cross-linked to DNA by photoactivated gilvocarcin $\mathrm{V}$ in human fibroblasts. Cancer Res 2000; 60: 3921-3926.

38. Ni M, Lee AS. ER chaperones in mammalian development and human diseases. FEBS Lett 2007; 581: 3641-3651

39. Waelter S, Boeddrich A, Lurz R, Scherzinger E, Lueder G, Lehrach H et al. Accumulation of mutant huntingtin fragments in aggresome-like inclusion bodies as a result of insufficient protein degradation. Mol Biol Cell 2001; 12: 1393-1407.

40. Adachi H, Katsuno M, Minamiyama M, Sang C, Pagoulatos G, Angelidis C et al. Heat shock protein 70 chaperone overexpression ameliorates phenotypes of the spinal and bulbar muscular atrophy transgenic mouse model by reducing nuclear-localized mutant androgen receptor protein. J Neurosci 2003; 23: 2203-2211.

41. Hoshino T, Nakaya T, Araki W, Suzuki K, Suzuki T, Mizushima T. Endoplasmic reticulum chaperones inhibit the production of amyloid-beta peptides. Biochem J 2007; 402: 581-589.

42. Kudo T, Imaizumi K, Hara H. A molecular chaperone inducer as potential therapeutic agent for neurodegenerative disease. Nihon Shinkei Seishin Yakurigaku Zasshi 2007; 27: 63-67.

43. Bolte S, Cordelieres FP. A guided tour into subcellular colocalization analysis in light microscopy. J Microsc 2006; 224: 213-232.

44. Lin JH, Li H, Yasumura D, Cohen HR, Zhang C, Panning B et al. IRE1 signaling affects cell fate during the unfolded protein response. Science 2007; 318: 944-949.

45. Wanker EE, Scherzinger E, Heiser V, Sittler A, Eickhoff H, Lehrach H. Membrane filter assay for detection of amyloid-like polyglutamine-containing protein aggregates. Methods Enzymol 1999; 309: 375-386.

46. Wu CY, Kang HY, Yang WL, Wu J, Jeong YS, Wang J et al. Critical role of monoubiquitination of histone $\mathrm{H} 2 \mathrm{AX}$ protein in histone $\mathrm{H} 2 \mathrm{AX}$ phosphorylation and DNA damage response. J Biol Chem 2011; 286: 30806-30815.

(c) (1) $(9)$ Cell Death and Disease is an open-access journal  licensed under a Creative Commons Attribution-NonCommercialNoDerivs 3.0 Unported License. To view a copy of this license, visit http://creativecommons.org/licenses/by-nc-nd/3.0/

Supplementary Information accompanies this paper on Cell Death and Disease website (http://www.nature.com/cddis) 